\title{
A Multipollutant Smoke Emissions Sensing and Sampling Instrument Package for Unmanned Aircraft Systems: Development and Testing
}

\author{
Kellen N. Nelson ${ }^{1,2, *}$, Jayne M. Boehmler ${ }^{1}$, Andrey Y. Khlystov ${ }^{1}{ }^{(0)}$, Hans Moosmüller ${ }^{1}{ }^{(0}$, \\ Vera Samburova $^{1}$, Chiranjivi Bhattarai ${ }^{1}\left(\mathbb{D}\right.$, Eric M. Wilcox ${ }^{1}\left(\mathbb{D}\right.$ and Adam C. Watts ${ }^{1, *(D)}$ \\ 1 Division of Atmospheric Sciences, Desert Research Institute, 2215 Raggio Parkway, Reno, NV 89512, USA; \\ Jayne.Boehmler@dri.edu (J.M.B.); Andrey.Khlystov@dri.edu (A.Y.K.); Hans.Moosmuller@dri.edu (H.M.); \\ Vera.Samburova@dri.edu (V.S.); Chiranjivi.Bhattarai@dri.edu (C.B.); Eric.Wilcox@dri.edu (E.M.W.) \\ 2 Department of Natural Resources and Environmental Sciences, University of Nevada-Reno, \\ 1664 N. Virginia St., Reno, NV 89557, USA \\ * Correspondence: kellennelson@unr.edu (K.N.N.); Adam.Watts@dri.edu (A.C.W.)
}

Received: 4 May 2019; Accepted: 4 June 2019; Published: 7 June 2019

\begin{abstract}
Poor air quality arising from prescribed and wildfire smoke emissions poses threats to human health and therefore must be taken into account for the planning and implementation of prescribed burns for reducing contemporary fuel loading and other management goals. To better understand how smoke properties vary as a function of fuel beds and environmental conditions, we developed and tested a compact portable instrument package that integrates direct air sampling with air quality and meteorology sensing, suitable for in situ data collection within burn units and as a payload on multi-rotor small unmanned aircraft systems (sUASs). Co-located sensors collect carbon dioxide, carbon monoxide, and particulate matter data at a sampling rate of $\sim 0.5 \mathrm{~Hz}$ with a microcontroller-based system that includes independent data logging, power systems, radio telemetry, and global positioning system data. Sensor data facilitates precise remote canister collection of air samples suitable for laboratory analysis of volatile organic compounds (VOCs) and other major and trace gases. Instrument package specifications are compatible with common protocols for ground-based and airborne measurements. We present and discuss design specifications for the system and preliminary data collected in controlled burns at Tall Timbers Research Station, FL, USA and Sycan Marsh Preserve, OR, USA.
\end{abstract}

Keywords: air quality; biomass burning; carbon dioxide; carbon monoxide; instrumentation; modified combustion efficiency; prescribed fire; particulate matter; smoke; unmanned aircraft systems; UAS; volatile organic compounds; VOCs; wildland fire

\section{Introduction}

Smoke from wildfires and prescribed fires degrades regional air quality and has consequences for human health [1], radiation budgets [2-4], and vegetation management activities used to reduce fire hazard and risk $[5,6]$. In recent decades, the impacts of smoke have piqued interest because of escalating wildfire activity due to climate warming and drought [7], and the widespread use of prescribed burning to reduce hazardous fuels. Emissions inventories estimate smoke production by pairing fuel consumption with emission factors-multiplication factors that convert the amount of fuel mass combustion to the amount of emissions released into the atmosphere [8,9]. Emissions factors for many gases and particulate matter (PM) remain uncertain and depend greatly on combustion processes that arise from the characteristics of fuel beds and weather conditions prior to and during burning $[8,10]$. 
Accurate emissions estimates from wildland fires are needed for reducing uncertainties in atmospheric chemical transport models and for improving predictions of fire effects on air quality [11,12].

Characterization and quantification of smoke emissions is difficult and complex due to the innate hazards associated with collecting measurements and samples in and near open burning areas, and also because smoke is highly dynamic in space and time. Laboratory burning is often favored due to safety and the practical convenience associated with combusting fuel and collecting smoke near precision instrumentation. However, laboratory conditions rarely reflect the range of environmental and fuel conditions present in the natural environment where wildland fires occur $[9,13]$. Field data collection is needed to overcome this limitation, and smoke emissions have a long history of being monitored with human-piloted aircraft and satellites $[14,15]$. Recent development of compact, lightweight instrumentation has expanded low altitude and mobile ground measurements of combustion emissions [13,16] and air quality [17]. Mobile aerial platforms including aerostats [13,18,19] and rotaryand fixed-wing small unmanned aircraft systems (sUASs) $[16,20]$ have come into favor for smoke measurement because they can maneuver into shifting smoke plumes and near combusting fuels while investigators maintain a safe distance from fire and airborne operations.

To better understand how smoke emissions vary with fuel beds and environmental conditions, we developed and tested a compact portable instrument package that integrates whole air sampling with air quality and meteorology sensing, suitable for ground and aerial emissions monitoring applications within and adjacent to burn units and as a mobile payload on multi-rotor sUASs. The sensing system monitors carbon monoxide $(\mathrm{CO})$, carbon dioxide $\left(\mathrm{CO}_{2}\right)$, and particulate matter $(\mathrm{PM})$ concentrations and fire weather conditions, and is suitable for characterizing spatial and temporal patterns of modified combustion efficiency and carbon fluxes in prescribed and wildfire smoke. The smoke sampling system enables the remote collection of air samples suitable for laboratory analysis of VOCs and other gases. We discuss the specifications and performance of the system and present data collected in a calibration experiment, and on controlled burns at Tall Timbers Research Station, FL, USA and Sycan Marsh Preserve, OR, USA.

\section{Materials and Methods}

A lightweight compact instrument package capable of collecting air samples and measuring $\mathrm{CO}$, $\mathrm{CO}_{2}$, and $\mathrm{PM}$ concentrations and fire weather conditions (i.e., temperature, relative humidity) was developed to characterize smoke plumes. This instrument package is suitable for airborne deployment on sUASs and stationary ground-based monitoring, and matches the desired specifications for the Fire and Smoke Model Evaluation Experiment (FASMEE)—Smoke and Emissions priority area [12,21]. The instrument package consists of two parts: (1) A measurement device ( 625 g) consisting of a sampling module that includes a solenoid valve system for collecting air samples and a sensing module for characterizing atmospheric gas concentrations and meteorological conditions in real-time, and (2) a radio-operated remote-control device $(\sim 145 \mathrm{~g})$ for initiating air sample collection and displaying time-series data from the sensing module. The sampling module permits air to flow on-demand into one or several evacuated 1000-mL volume SilcoCan canisters (RESTEK, Bellefonte, PA, USA) that are returned to the lab for specialized analysis capable of enumerating of up to 100 VOCs and other trace gases. In this configuration, a power supply operates the solenoid valves, allowing for up to eight sampling ports (i.e., valves) to be accommodated. The sensing module includes regulated air flow across $\mathrm{CO}$ and $\mathrm{CO}_{2}$ sensors using custom inline flow caps designed to draw the sample over the diffusion medium with a $\sim 0.5 \mathrm{~L} / \mathrm{min}$ micropump (Figure 1). A custom low-volume flow cap was designed and 3D printed for the $\mathrm{CO}$ sensor and a commercial flow cap was purchased for the $\mathrm{CO}_{2}$ sensor. The PM sensor was mounted in an external cutout in the enclosure and contains a built-in fan to control air flow. The measurement device is housed in a rectangular, weather resistant box $(24.8 \times 19.7 \times 7.1 \mathrm{~cm})$. Both devices can be powered using a 5 to $18 \mathrm{~V}$ supply and can operate for several hours using a standard $9 \mathrm{~V}$ battery. Teensy 3.6 and 3.2 microcontrollers (PJRC, Sherwood, OR, USA) control signal processing for the measurement and remote control devices, respectively. 


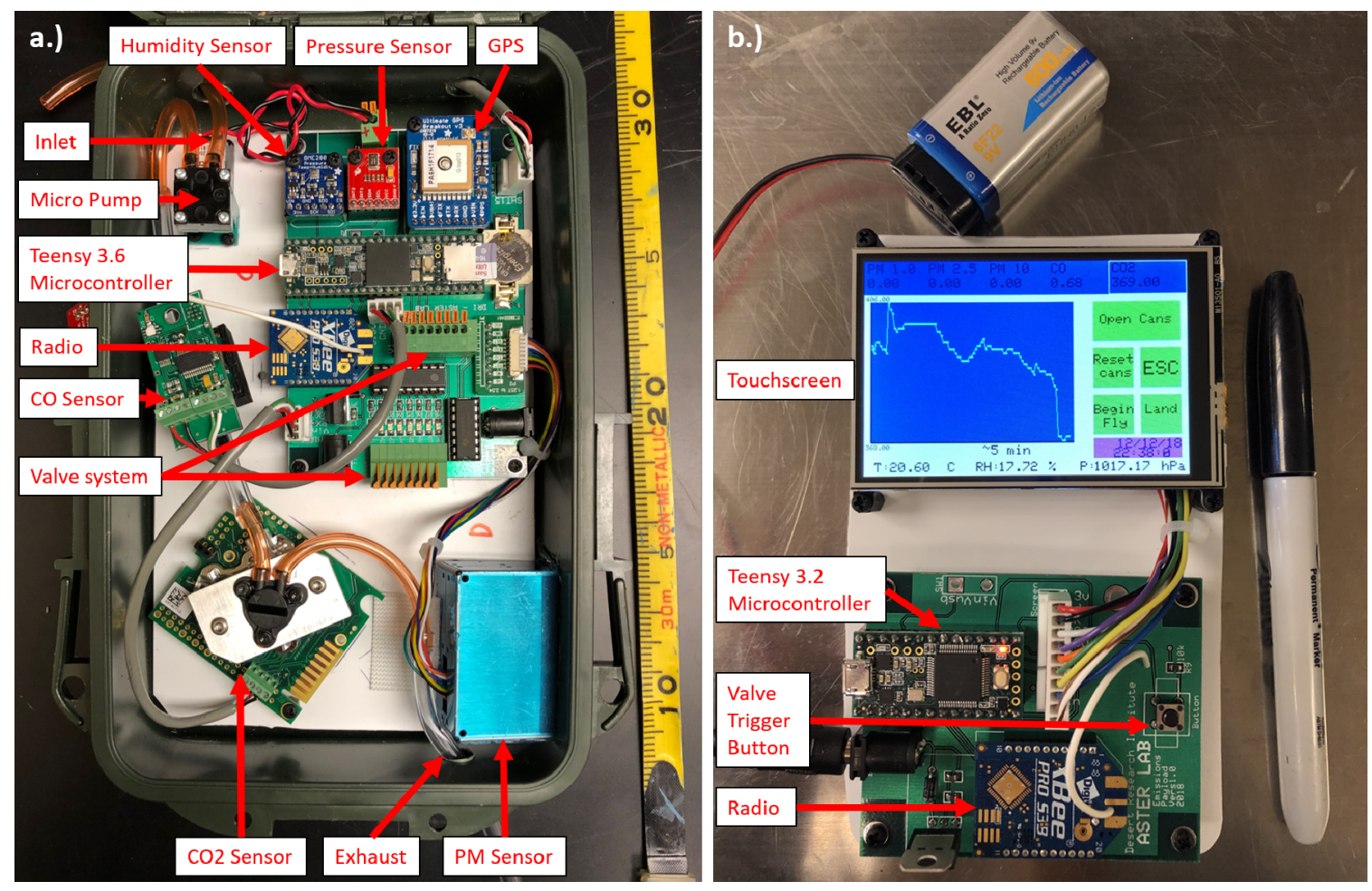

Figure 1. Instrument design and components. (a) The measurement device houses the main circuit board, including the Teensy 3.6 microcontroller and sensors. The $\mathrm{CO}$ and $\mathrm{CO}_{2}$ sensors are plumbed in line with a micropump and the particulate matter sensor is exposed to ambient air through a window on the side of the enclosure. (b) The remote-control device displays real-time data from sensors and is used to manually trigger valves for canister sample collection.

\subsection{Instrument Components}

\subsubsection{Teensy 3.6/3.2 Microcontroller Units}

Payload device executions were carried out using the Teensy 3.6 microcontroller (PJRC, Sherwood, OR, USA), a 32-bit $180 \mathrm{MHz}$ advanced reduced instruction set computer machine processor with 62 input/output pins and 13-bit analog read resolution. The Teensy 3.6 features a built-in Secure Digital Input/Output port used for saving data to a micro Secure Digital (i.e., microSD) card and a built-in real-time clock (RTC) provides timekeeping. The remote-control device used the smaller Teensy 3.2 (PJRC, Sherwood, OR, USA) with a slower rated speed (72 MHz) and fewer digital pins. The Arduino Integrated Development Environment, an open-source software, was used to program both microcontrollers in a C-based language.

\subsubsection{K-30 Carbon Dioxide Sensor}

Carbon dioxide measurements were obtained using the $\mathrm{K}-30 \mathrm{CO}_{2}$ sensor (Senseair, Delsbo, Sweden). The K-30 is a non-dispersive infrared (NDIR) sensor that outputs $\mathrm{CO}_{2}$ concentrations from 0 to $10,000 \mathrm{ppm}$ with an accuracy of $\pm 30 \mathrm{ppm}$, or $\pm 3 \%$, up to $5000 \mathrm{ppm}$ and a diffusion time $\left(\mathrm{T}_{1 / \mathrm{e}}\right)$ of $\sim 20 \mathrm{~s}$. Additional specifications are shown in Supplementary Table S1.

\subsubsection{DGS-CO 968-034 Carbon Monoxide Sensor}

Carbon monoxide measurements were obtained using the DGS-CO 968-034 CO Sensor (Spec Sensors LLC, Newark, CA, USA). The DGS-CO 968-034 is a digital electrochemical gas sensor that outputs carbon monoxide concentrations from 0 to $1000 \mathrm{ppm}$ with $0.1 \mathrm{ppm}$ resolution and an accuracy of $\pm 15 \%$. The chemical sensor has a manufacturer stated time response $\left(T_{90}\right)$ of $30 \mathrm{~s}$. The $\mathrm{CO}$ sensor exhibits low 
cross-sensitivity to other combustion gases with a $<1 \mathrm{ppm}$ response in $\mathrm{CO}$ at concentrations of $5000 \mathrm{ppm}$ $\mathrm{CO}_{2}, 3000$ ppm $\mathrm{CH}_{4}, 10$ ppm $\mathrm{NO}_{2}, 25$ ppm $\mathrm{H}_{2} \mathrm{~S}, 500$ ppm n-Heptane, and 200 ppm Toluene, and a $17 \mathrm{ppm}$ response in CO at $100 \mathrm{ppm}$ H. Additional specifications are shown in Supplementary Table S1.

\subsubsection{PMS5003 Particulate Matter Sensor}

Particulate matter measurements were obtained using the PMS5003 sensor (Plantower, Beijing, China). The PMS5003 is a compact laser scattering sensor that outputs mass concentrations $\left(\mu \mathrm{g} \mathrm{m}^{-3}\right)$ for $\mathrm{PM}_{1.0}, \mathrm{PM}_{2.5}$, and $\mathrm{PM}_{10}$ at a $1 \mu \mathrm{g} \mathrm{m}^{-3}$ resolution with a minimum particle diameter of $0.3 \mu \mathrm{m}$ and includes the number of particles per unit volume for various particle size ranging between $0.3 \mu \mathrm{m}$ and $10.0 \mu \mathrm{m}$. Mass concentration data is output in standard particle and atmospheric environment units, and we report data in atmospheric environment units. Additional specifications are shown in Supplementary Table S1.

\subsubsection{Global Positioning System (GPS)}

Time and position data were obtained using an Adafruit Ultimate GPS breakout board (Adafruit Industries, New York, NY, USA). The position is output with a $3 \mathrm{~m}$ accuracy and includes time and date at a capture rate up to $10 \mathrm{~Hz}$.

\subsubsection{BME 280 Humidity Sensor}

Relative humidity, ambient temperature, and barometric pressure were obtained using the BME 280 (Bosch Sensortec, Reutlingen/Kusterdingen, Germany). The BME 280 sensor has an accuracy tolerance of $\pm 3.0 \%$. The BME280 was placed inside of the instrument housing for internal temperature readings and was used for investigating the temperature dependence of the $\mathrm{CO}$ and $\mathrm{CO}_{2}$ sensors (see Section 2.2).

\subsubsection{SHT-15 Temperature Sensor}

Ambient temperature and relative humidity were obtained using the SHT-15 sensor (Sensirion, Staefa ZH, Switzerland). The SHT-15 is a complementary metal-oxide semiconductor digital sensor with an accuracy of $\pm 0.3{ }^{\circ} \mathrm{C}$ for temperature and $\pm 2.0 \%$ relative humidity. Measurements were used to evaluate environmental conditions outside of the instrument housing.

\subsubsection{MPL3115A2 Pressure Sensor}

Absolute pressure was measured using the MPL3115A2 sensor (NXP Semiconductors, The Netherlands). The MPL3115A2 sensor is a piezoresistive sensor with a 1.5 Pa pressure resolution, is internally temperature compensated, and was adjusted to sea level pressure using the US Standard Atmosphere 1976 protocol [22].

\subsubsection{Micropump}

We used a $0.5 \mathrm{~L} \mathrm{~min}^{-1}$ flowrate diaphragm pump (Thomas by Gardner Denver, Sheboygan, WI, USA) to control the flow through the chemical sensors. The pump runs on a $5 \mathrm{~V}$ direct current from the printed circuit board and operated continuously while measurements were being collected. Air is drawn from outside the instrument housing and pushed across the $\mathrm{CO}$ and $\mathrm{CO}_{2}$ sensors to ensure that both sensors measure the same air sample.

\subsubsection{XBee Pro S3B Radio Module}

Two-way communication between the payload and the remote control device was facilitated with $900 \mathrm{MHz}$ XBee radio modules (Digi International, Hopkins, MN, USA). These modules can communicate with a data-transfer rate of 10 to $200 \mathrm{~kb} \mathrm{~s}^{-1}$ over a 6.5 to $15.5 \mathrm{~km}$ line-of-sight distance. 


\subsubsection{Adafruit Featherwing Touch Screen}

Data transmitted between the measurement and remote controller devices were displayed on a $8.9 \mathrm{~cm}$ touch screen with a $480 \times 320$ pixel resolution (Adafruit Industries, New York, NY, USA). A graphical user interface permits sending instructions to initiate air sample collection to the measurement device and also displays real-time $\mathrm{CO}, \mathrm{CO}_{2}, \mathrm{PM}_{1.0}, \mathrm{PM}_{2.5}$, and $\mathrm{PM}_{10}$ concentration data as time-series. Data display can be used to determine when conditions are appropriate for collecting air samples, such as when the instrument package is within the target smoke plume. The screen also displays the temperature, pressure, relative humidity, date, and time readings from the measurement device.

\subsection{Instrument Performance Experiments}

We investigated the $\mathrm{CO}$ and $\mathrm{CO}_{2}$ sensor performance and developed span and offset calibration correction factors by constructing three complete sensing instruments and testing them on a calibration system where standard gas concentrations were systematically varied using a computerized gas mixer and delivered via in line plumbing to each measurement device instrument (Figure 2). Each instrument was tested individually on the calibration system using the same experimental procedure. Data for each sensing instrument reflected observations collected during a single calibration experiment and were evaluated separately to judge consistency in sensor performance and together to evaluate the efficacy of using a global calibration model across multiple instruments. The experimental procedure consisted of diluting concentrated standard gas (1800 ppm CO: $22.5 \% \mathrm{CO}_{2}$ ) with zero air using a gas mixer (Environics, Inc., Tolland, CT, USA) capable of dilution ratios spanning 1:20 to 1:2000 at flow rates ranging from 2 to $20 \mathrm{~L} \mathrm{~min}^{-1}$ with the concentration and flow accuracy reported to be $\pm 1 \%$. The gas mixer was programmed to alternate gas concentrations between five minute periods of "background" gas (i.e., $3.2 \mathrm{ppm} \mathrm{CO}$ and $400 \mathrm{ppm} \mathrm{CO}_{2}$ ) and seven minute periods of progressively higher concentrations reflecting the following target $\mathrm{CO}$ and $\mathrm{CO}_{2}$ concentrations: 8/1000, 16/2000, $24 / 3000$, and $32 / 4000 \mathrm{ppm}$, respectively. Output concentrations from the mixer did not exactly match target concentrations owing to the high concentration of our standard and the dilution ratios/flow rates offered by the mixer. Sensing instruments collected data at $0.5 \mathrm{~Hz}$. $\mathrm{CO}$ and $\mathrm{CO}_{2}$ sensor output was compared against two industry standard analyzers: a LI-7000 (LI-COR, Lincoln, NE, USA) for $\mathrm{CO}_{2}$ and a CO Analyzer Model 8830 (TeleDyne Monitor Labs, Englewood, CO, USA) for CO. The PM sensor has been evaluated in other studies (e.g., [23-26]) and further evaluation of the Plantower PMS5003 PM sensor was not completed as part of the present study.

Span and offset calibration correction factors were computed by fitting linear regression calibration models, and calibrated signal concentrations and model uncertainty were estimated using inverse regression [27]. Models took the form, $y=m x+b$, where $y$ is the sensor response, $x$ is the input concentration generated by the gas mixer, $\mathrm{m}$ is the model slope (i.e., span), and $\mathrm{b}$ is the model intercept (i.e., offset). Calibration model data had a sample size of $n=5$ for each sensing instrument and were prepared by computing the mean input concentration supplied by the gas mixer and mean sensor response concentration from a 2-minute subset of the time series that corresponded with each concentration level. Global models were fit by combining data across all instrument calibration experiments and concentrations $(n=15)$.

To examine variation in the sensor accuracy, precision, and response time among instruments, we applied instrument specific and global calibration models to raw $\mathrm{CO}$ and $\mathrm{CO}_{2}$ data and computed descriptive statistics using one two-minute subset of data at each concentration level ( $\mathrm{n}=60$ samples per concentration level at $0.5 \mathrm{~Hz}$ over 2 minutes). Sensor accuracy was assessed by investigating absolute and relative percent error rates, and sensor precision was judged using standard deviation. Absolute error was computed as the difference between sensor and mixer (i.e., true) concentrations, and the relative percent error was computed as the absolute error divided by the mixer concentration times $100 \% . \mathrm{T}_{90}$ response time, the time required for a sensor exposed to the background concentration to achieve $90 \%$ of the applied concentration, was computed for each sensor and target concentration level. Sensor temperature sensitivity was investigated by cooling the measurement device to ambient 
outdoor temperature $\left(\sim 10^{\circ} \mathrm{C}\right)$, then transferring the device to a drying oven and warming the device over $15 \mathrm{~min}$ to $40^{\circ} \mathrm{C}$. Background gas concentrations were held constant by enclosing the measurement instrument in a sealed plastic bag. The $\mathrm{CO}$ sensor provided internal temperature compensation and was not examined further.

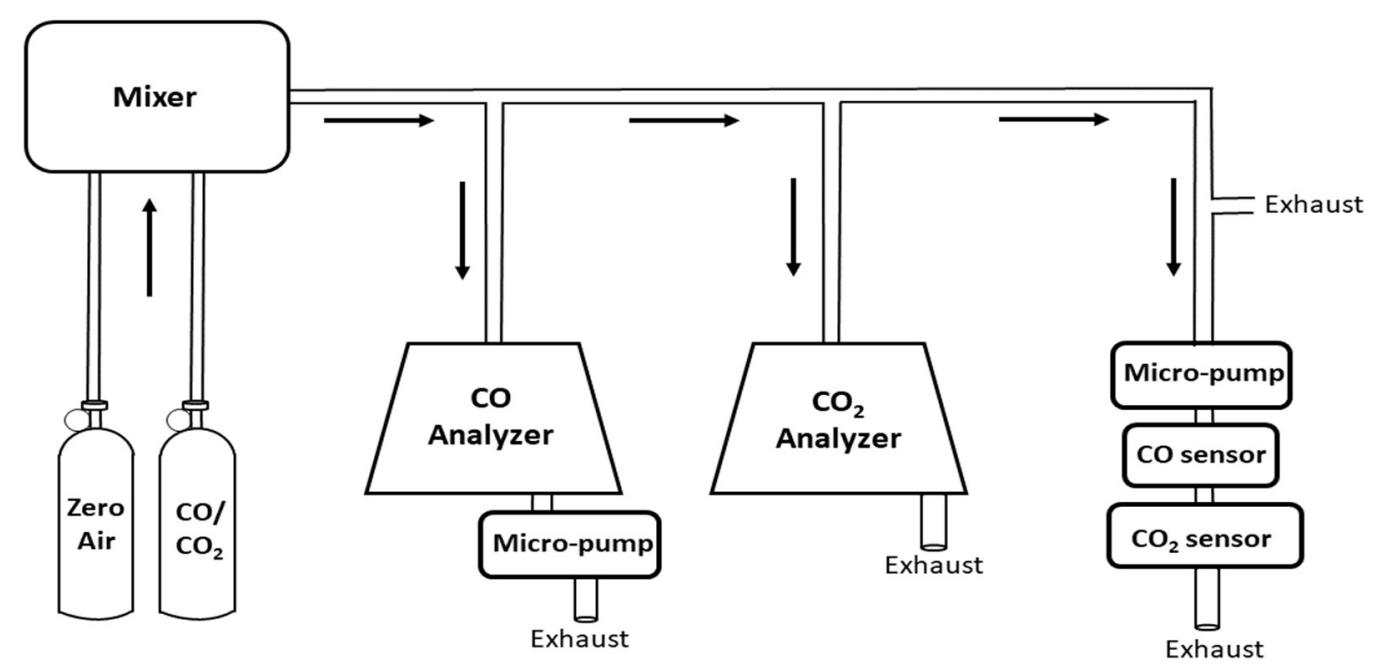

Figure 2. Experimental system used for calibrating each of the three sensing instruments that included carbon monoxide and carbon dioxide sensors. Standard gases were diluted with zero air using an environmental gas mixer and delivered to standard gas monitors and measurement instrument sensors. Sensing instruments were tested separately on the system.

\subsection{Field Testing}

The sampling and sensing modules were tested separately in experimental prescribed fires at Tall Timbers Research Station, FL, USA and Sycan Marsh Preserve, OR, USA, respectively. Only one instrument was available for sampling in each field campaign.

\subsubsection{Tall Timbers Research Station, FL, USA}

The sampling module was deployed to collect smoke samples from experimental prescribed fires near the Tall Timbers Research Station north of Tallahassee, FL, USA ( $\left.30^{\circ} 39^{\prime} 19^{\prime \prime} \mathrm{N} 84^{\circ} 13^{\prime} 33^{\prime \prime} \mathrm{W}\right)$. On April 18, 2018, a 2-ha burn was conducted at the Pebble Hill site and on April 20, 2018, a 40-ha burn was conducted at the Scrub Course site. Vegetation at the Pebble Hill site is dominated by longleaf pine-wiregrass (Pinus palustris-Aristida beyrichiana) savanna with sparse understory fuels due to frequent (every $\sim 2$ to 3 years) prescribed burns. The Scrub Course site includes additional overstory of turkey oak (Quercus laevis), mockernut (Carya tomentosa), and pignut hickory (Carya glabra), which are being reduced by intentional frequent prescribed fires to restore the landscape to a historic longleaf pine-wiregrass ecosystem. To collect samples, the sampling device and up to three evacuated $1000 \mathrm{~mL}$ volume SilcoCan sample canisters were mounted on a custom aluminum rack under a DJI Matrice 600 Pro hexacopter sUAS that measured $52.5 \times 48.0 \times 64.0 \mathrm{~cm}$ with a weight of $10 \mathrm{~kg}$ (including batteries) and a recommended payload capacity of $5.5 \mathrm{~kg}$ (Supplementary Figure S1). As configured, the payload weight was $2.6 \mathrm{~kg}$ (including 1 sample canister weighing $0.9 \mathrm{~kg}$ ) and the sUAS endurance was $\sim 20$ minutes. Additional canisters were added depending on the sampling mission objectives; however, the UAS payload capacity and canister weight currently limit our ability to lift more than 4 canisters at a time. The sUAS and its payload were manually piloted into the smoke plume at $25 \mathrm{~m}$ above ground-level. $\mathrm{CO}_{2}$ and $\mathrm{PM}$ data transmitted from a preliminary version of the sensing module provided confirmation that the payload was in the smoke plume. Samples were collected by remotely triggering the solenoid valve system with the remote-control device, allowing smoke to flow into the evacuated canister for $10 \mathrm{~s}$. After sampling, canisters were capped and shipped to the Organic Analysis 
Lab (https://www.dri.edu/oal-lab) of the Desert Research Institute, Reno, NV, USA and processed for VOC content.

Stainless steel SilcoCan canisters of a $1000 \mathrm{~mL}$ capacity were cleaned prior to sampling by repeated evacuation and pressurization with humidified ultra-high purity (UHP) nitrogen (Airgas, Sparks, NV, USA) following the U.S. Environmental Protection Agency (EPA) protocol [28,29]. Eight cycles of evacuation to $\sim 25$ in $\mathrm{Hg}$ vacuum followed by pressurization to $\sim 15$ psig were performed to clean the canisters. One canister per lot was filled with humidified UHP nitrogen and analyzed by gas chromatograph with mass spectrometric and flame ionization detectors (GC-MS/FID), as described below. The canisters were considered clean if the target compound concentrations were less than 0.05 ppbv.

Canister samples were analyzed for 74 VOC species using GC-MS/FID according to the EPA Method TO-15 [30]. The GC-MS/FID includes a Lotus Consulting Ultra-Trace Toxics sample preconcentration system built into a Varian 3800 gas chromatograph coupled to a Saturn 2000 ion trap mass spectrometer (Varian, Inc. Walnut Creek, CA, USA). The Lotus preconcentration system consists of three traps. Mid- and heavier weight hydrocarbons are trapped on the front trap consisting of $1 / 8^{\prime \prime}$ nickel tubing packed with multiple adsorbents. Trapping is performed at $55^{\circ} \mathrm{C}$ and eluting is performed at $200{ }^{\circ} \mathrm{C}$. The rear traps consist of two traps: Empty $0.040^{\prime \prime}$ ID nickel tubing for trapping light hydrocarbons and a cryo-focusing trap for mid and higher weight hydrocarbons isolated in the front trap. The cryo-focusing trap is built from $6^{\prime} \times 1 / 8^{\prime \prime}$ nickel tubing filled with glass beads. Trapping of both rear traps occurs at $-180{ }^{\circ} \mathrm{C}$ and eluting at $200{ }^{\circ} \mathrm{C}$. Light hydrocarbons are deposited to a Varian CP-Sil5 column $(15 \mathrm{~m} \times 0.32 \mathrm{~mm} \times 1 \mu \mathrm{m})$ plumbed to a column-switching valve in the GC oven, then to a Chrompack $\mathrm{Al} 2 \mathrm{O} 3 / \mathrm{KCl}$ column $(25 \mathrm{~m} \times 0.53 \mathrm{~mm} \times 10 \mu \mathrm{m})$ leading to the FID for quantitation of light hydrocarbons. The mid-range and heavier hydrocarbons cryo-focused in the rear trap are deposited to a J\&W DB-1 column $(60 \mathrm{~m} \times 0.32 \mathrm{~mm} \times 1 \mu \mathrm{m})$ connected to the MS. The GC initial temperature was $5^{\circ} \mathrm{C}$ and was held for approximately $9.5 \mathrm{~min}$, then increased at $3^{\circ} \mathrm{C} \mathrm{min}-1$ to $200{ }^{\circ} \mathrm{C}$ for a total run time of $80 \mathrm{~min}$.

The GC-MS/FID response for individual VOCs was calibrated with a compressed gas mixture (Apel-Riemer, Environmental, Inc., Miami, FL, USA) containing 74 hydrocarbons ranging in size from ethane to n-undecane at 0.2 to $10 \mathrm{ppbv}$ concentrations. Replicate analyses were performed at least for one in every 10 injections. The minimum detection limit (MDL) was approximately $0.01 \mathrm{ppbv}$. The replicate precision of the GC-MS/FID method was $\sim 8 \%$ for all analyzed compounds.

\subsubsection{Sycan Marsh Preserve, OR, USA}

The sensing module was deployed to monitor $\mathrm{CO}, \mathrm{CO}_{2}$, and PM concentrations and meteorological conditions (i.e., temperature, relative humidity) in an experimental prescribed fire at Sycan Marsh Preserve (The Nature Conservancy) in Oregon's Upper Klamath Basin ( $42^{\circ} 48^{\prime} 32.4^{\prime \prime}$ N 121 $07^{\prime} 01.1^{\prime \prime}$ W) north-west of Lakeview, OR, USA. On October 24, 2018, a prescribed burn was conducted at Brattain Ridge, a site occupied by ponderosa pine (Pinus ponderosa) and western juniper (Juniperus occidentalis) with a sagebrush (Artemisia tridentata)/bitterbrush (Purshia tridentata) shrub understory and a surface fuelbed of needle litter and senesced annual grasses. The sensing device was hung at 8-m height from a ponderosa pine branch (using a pole pruner) to monitor the full temporal profile of gas concentrations and temperature and relative humidity conditions as a head fire passed under the sensing device (Supplementary Figure S1). The sUAS was not used for sampling because battery replacement would have interrupted the sampling of the time series. The device was calibrated in the laboratory prior to deployment in the field and $\mathrm{CO}_{2}$ data exhibited minor signs of noise (varying $\pm 40 \mathrm{ppm}$ at ambient concentrations). This noise was later resolved in laboratory testing (prior to the calibration experiments) by adding shielding to the K-30 sensor. Data were collected at $\sim 0.5 \mathrm{~Hz}$ and boxcar smoothing was applied to reduce sensor noise (i.e., each data point was replaced by the mean of $\mathrm{m}$ number of adjacent points $(m=60 / 2)$ ). The modified combustion efficiency (MCE) was computed using the smoothed data as the ratio of the excess $\mathrm{CO}_{2}$ concentration to the sum of excess $\mathrm{CO}$ and $\mathrm{CO}_{2}$ concentrations $(\mathrm{MCE}=$ $\left.\Delta \mathrm{CO}_{2} /\left(\Delta \mathrm{CO}+\Delta \mathrm{CO}_{2}\right)\right)$. 
All data processing and statistical analysis was conducted in the R software program using the following r-packages: Base [31], EnvStats [27], lubridate [32], tibbletime [33], and tidyverse [34].

\section{Results and Discussion}

\subsection{Gas Sensor Performance}

CO calibration models for individual sensors exhibited high correlation coefficients $\left(\mathrm{r}^{2}=0.99\right)$, indicating strong statistical relationships between sensor readings and calibration gas concentrations. A global calibration model using data from all sensors resulted in a poorer fit $\left(r^{2}=0.94\right.$, Table 1$)$ and greater absolute and relative error rates than individually calibrated sensors.

Table 1. Individual and global regression calibration model results for Spec Sensors DGS-CO 968-034 carbon monoxide (CO) sensors.

\begin{tabular}{lccccc}
\hline & Coefficient & SE & $\mathbf{t}$ & $p$ & $\mathbf{r}^{\mathbf{2}}$ \\
\hline Instrument 1 & & & & & \\
$\quad$ Intercept & 10.975 & 0.19 & 58.326 & $<0.001$ & 0.999 \\
$\quad$ Raw CO (ppm) & 1.516 & 0.01 & 166.347 & $<0.001$ & \\
Instrument 2 & & & & & \\
$\quad$ Intercept & 7.633 & 0.35 & 21.8 & $<0.001$ & 0.999 \\
$\quad$ Raw CO (ppm) & 1.492 & 0.02 & 87.968 & $<0.001$ & \\
Instrument 3 & & & & & \\
$\quad$ Intercept & 17.773 & 0.15 & 118.261 & $<0.001$ & 0.999 \\
$\quad$ Raw CO (ppm) & 1.483 & 0.01 & 203.794 & $<0.001$ & \\
Global (All Instruments) & & & & & \\
$\quad$ Intercept & 12.123 & 2.14 & 5.655 & $<0.001$ & 0.941 \\
$\quad$ Raw CO (ppm) & 1.497 & 0.1 & 14.42 & $<0.001$ & \\
\hline
\end{tabular}

Span coefficients for CO ranged from 1.48 $\pm 0.01 \mathrm{SE}$ to $1.52 \pm 0.01 \mathrm{SE}$ with a global model span coefficient of $1.50 \pm 0.10 \mathrm{SE}$, where tolerances are denoting standard errors (SE). Offsets ranged from $7.63 \pm 0.35 \mathrm{SE}$ to $17.77 \pm 0.15 \mathrm{SE}$ ppm with a global offset of $12.12 \pm 2.14 \mathrm{SE}$ ppm. Absolute error across individually calibrated sensors ranged from $0.02 \pm 0.38$ SD ppm at $16 \mathrm{ppm}$ to $0.13 \pm 0.33 \mathrm{ppm}$ at $3.2 \mathrm{ppm}$ with an overall absolute error of $0.01 \pm 0.45 \mathrm{SD} \mathrm{ppm}$, where tolerances are denoting standard deviations (SD). Standard deviation ranged from $0.33 \mathrm{ppm}$ at $3.2 \mathrm{ppm}$ to $0.50 \mathrm{ppm}$ at $32 \mathrm{ppm}$ for all sensors calibrated individually (Figure 3). Percent relative error across individually calibrated sensors ranged from $1.5 \pm 0.4 \mathrm{SD} \%$ at $32 \mathrm{ppm}$ to $9.7 \pm 4.9 \mathrm{SD} \%$ at $3.2 \mathrm{ppm}$ with an overall rate of $4.0 \pm 4.0 \mathrm{SD} \%$ (Figure 3). In all cases, the relative error rates for Spec Sensors DGS-CO 968-034 CO sensor performed better than the manufacturer stated measurement error rate of $\pm 15 \%$. The Monitor Labs Inc. CO Analyzer Model 8830 exhibited improved accuracy over our low-cost CO sensors under calibration, with relative error rates ranging from $1.0 \pm 0.7 \mathrm{SD} \%$ at $32 \mathrm{ppm}$ to $8.3 \pm 5.8 \mathrm{SD} \%$ at $3.2 \mathrm{ppm}$ with an overall error rate of $2.9 \pm 3.9 \mathrm{SD} \%$. The relative difference between the calibrated $\mathrm{CO}$ Analyzer Model 8830 and the DGS-CO 968-034 CO sensors was $3.3 \pm 4.4$ SD \%. Both absolute and relative error rates for the DGS-CO 968-034 CO sensor were greater than those of the Citicell electrolytic CO sensor used by Ward et al. [35,36], but similar, if not slightly better, than those of the EC4-500-CO sensor. It is important to note that the range of concentrations in our calibration was smaller than those used in calibrating the EC4-500-CO [16]. Using the global calibration model, the mean absolute error was approximately double and the SD was $~ 10$ times greater than that found in individual sensor calibrations and ranged from $0.05 \pm 2.81 \mathrm{SD}$ ppm at $16 \mathrm{ppm}$ to $0.26 \pm 2.66 \mathrm{ppm}$ at $24 \mathrm{ppm}$ with an overall absolute error of $0.03 \pm 2.80 \mathrm{SD}$ ppm. The relative error was substantially higher using the global calibration model, ranging from $7.3 \pm 3.9 \mathrm{SD} \%$ at $32 \mathrm{ppm}$ to $80.0 \pm 38.0 \%$ at $3.2 \mathrm{ppm}$ with an overall absolute error of $27.9 \pm 33.1$ SD\% (Figure 3). Overall, the Spec DGS-CO 968-034 sensor performed well when calibrated individually, but variation between sensors resulted in high absolute and relative error rates, suggesting that the use of a global calibration model is inappropriate for this sensor. 

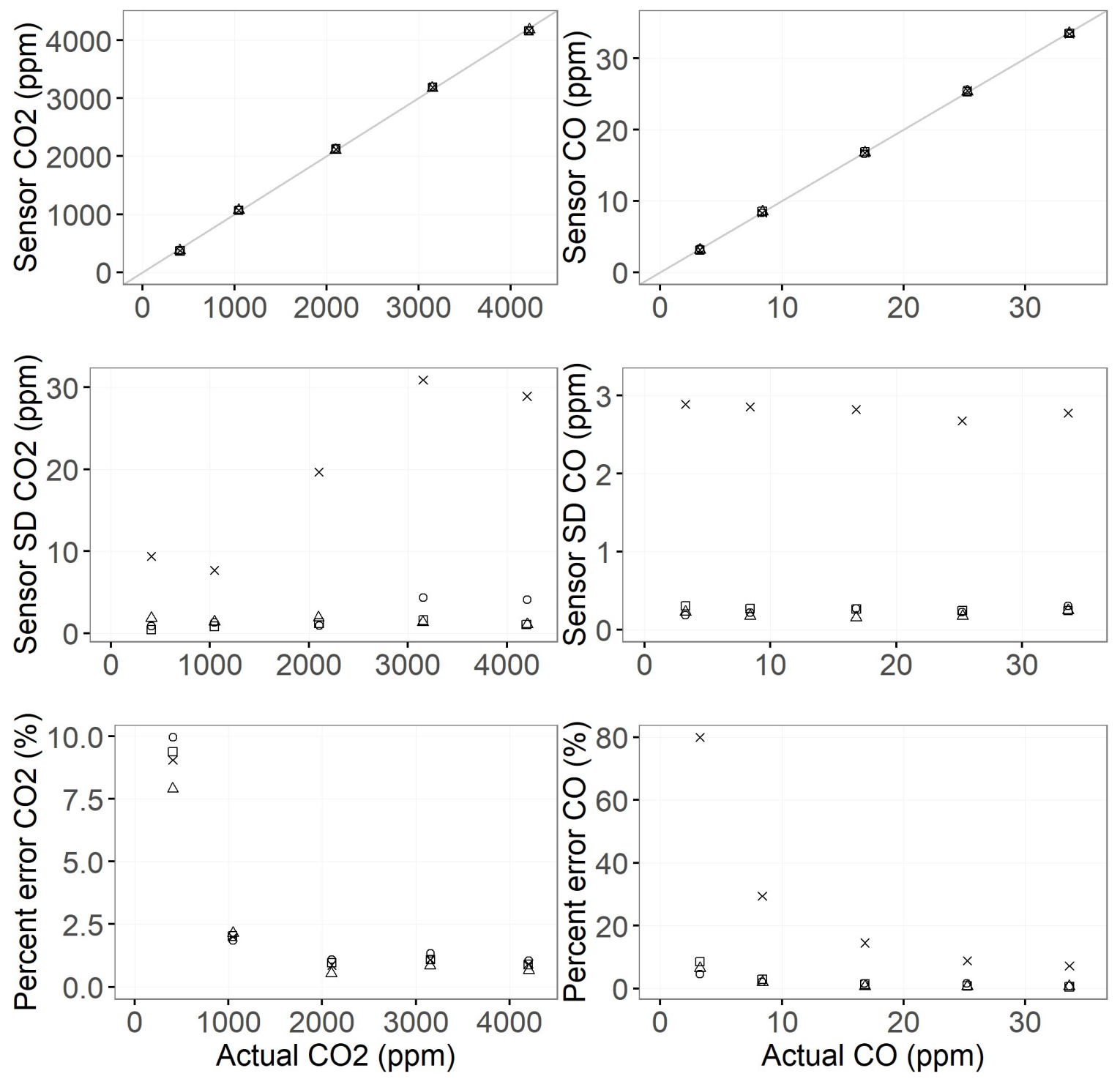

\section{Instrument $\triangle 1 \quad 1 \quad 2 \quad \Delta \quad 3 \times$ All}

Figure 3. Gas concentration, standard deviation, and relative error rates for calibrated Senseair K-30 carbon dioxide and Spec Sensors DGS-CO 968-034 carbon monoxide sensors versus actual gas concentration delivered by the environmental gas mixer.

$\mathrm{CO}_{2}$ calibration models exhibited high correlation coefficients for both individual and global models $\left(\mathrm{r}^{2}=0.99\right.$, Table 2$)$, and equivalent absolute and relative error rates, suggesting that individual and global calibration models are appropriate for use with the Senseair K-30 $\mathrm{CO}_{2}$ sensor. Span coefficients ranged from $0.695 \pm 0.007 \mathrm{SE}$ to $0.710 \pm 0.011 \mathrm{SE}$ with a global model span coefficient of $0.701 \pm 0.005 \mathrm{SE}$. Offsets ranged from $143.947 \pm 27.171 \mathrm{SE}$ to $157.002 \pm 18.807 \mathrm{SE}$ ppm with a global offset of $148.439 \pm 13.374 \mathrm{SE}$ ppm. Absolute error across individually calibrated sensors ranged from $18.1 \pm 5.5 \mathrm{SD}$ ppm at $2000 \mathrm{ppm}$ to $36.9 \pm 3.7 \mathrm{ppm}$ at $400 \mathrm{ppm}$ with an overall absolute error of $0.01 \pm 30.9$ SD ppm. Standard deviation ranged from $1.9 \mathrm{ppm}$ at $1000 \mathrm{ppm}$ to $8.7 \mathrm{ppm}$ at $3000 \mathrm{ppm}$ for all sensors calibrated individually (Figure 3). Absolute error rates using the global calibration model were nearly identical; SD was nominally greater, ranging from $18.1 \pm 18.1 \mathrm{SD}$ ppm at $2000 \mathrm{ppm}$ to $36.8 \pm 9.6 \mathrm{ppm}$ at $400 \mathrm{ppm}$ with an overall absolute error of $0.01 \pm 36.7 \mathrm{SD} \mathrm{ppm}$. Relative error across individually calibrated sensors ranged from $0.9 \pm 0.3 \mathrm{SD} \%$ at $2000 \mathrm{ppm}$ to $9.1 \pm 0.9 \mathrm{SD} \%$ at $400 \mathrm{ppm}$ with an overall 
rate of $2.8 \pm 3.2 \mathrm{SD} \%$ (Figure 3). Similarly, relative error when using the global calibration model ranged from $0.9 \pm 0.9 \mathrm{SD} \%$ at $2000 \mathrm{ppm}$ to $9.1 \pm 2.4 \%$ at $400 \mathrm{ppm}$ with an overall absolute error of $2.8 \pm 3.4$ $\mathrm{SD} \%$ (Figure 3). Overall concentrations, and absolute and relative percent error rates for the Senseair $\mathrm{K}-30 \mathrm{CO}_{2}$ sensor were within manufacturer stated measurement error rates; however, error rates at our lowest concentration $(400 \mathrm{ppm})$ were greater than the manufacturer stated error rate $( \pm 30 \mathrm{ppm}$ or $\pm 3 \%$ of the measured value, whichever is greater). For comparison, the Li-COR LI-7000 exhibited favorable relative error rates ranging from $0.1 \pm 0.1 \mathrm{SD} \%$ at $3000 \mathrm{ppm}$ to $2.6 \pm 0.4 \mathrm{SD} \%$ at $400 \mathrm{ppm}$ with an overall error rate of $1.0 \pm 0.9 \mathrm{SD} \%$. The relative difference between the calibrated LI-7000 and $\mathrm{K}-30 \mathrm{CO}_{2}$ sensors was $3.7 \pm 4.6 \mathrm{SD} \%$. Absolute and relative error rates for the $\mathrm{K}-30$ sensor were greater than those found for the DX6220 $\mathrm{CO}_{2}$ sensor [16] and the Valtronics (model $2015 \mathrm{BMC}$ ) $\mathrm{CO}_{2}$ sensor employed by Ward et al. [35,36]. Similar to the findings by Yasuda et al. [37], no temperature dependence of the offset was observed for the $\mathrm{CO}_{2}$ sensor at ambient concentrations and for a temperature range of 10 to $40^{\circ} \mathrm{C}$.

Table 2. Individual and global regression calibration model results for Senseair K-30 carbon dioxide $\left(\mathrm{CO}_{2}\right)$ sensors.

\begin{tabular}{lccccc}
\hline & Coefficient & SE & $\mathbf{t}$ & $p$ & $\mathbf{r}^{2}$ \\
\hline Instrument 1 & & & & & \\
$\quad$ Intercept & 144.389 & 23.6 & 6.107 & 0.009 & 0.999 \\
$\quad$ Raw $\mathrm{CO}_{2}(\mathrm{ppm})$ & 0.698 & 0.01 & 76.202 & $<0.001$ & \\
Instrument 2 & & & & & \\
$\quad$ Intercept & 143.947 & 27.2 & 5.298 & 0.013 & 0.999 \\
$\quad$ Raw $\mathrm{CO}_{2}$ (ppm) & 0.71 & 0.01 & 67.442 & $<0.001$ & \\
Instrument 3 & & & & & \\
$\quad$ Intercept & 157.002 & 18.8 & 8.348 & 0.004 & 0.999 \\
$\quad$ Raw CO $\mathrm{CO}_{2}$ (ppm) & 0.695 & 0.01 & 95.309 & $<0.001$ & \\
Global (All Instruments) & 148.439 & 13.4 & 11.099 & $<0.001$ & 0.999 \\
$\quad$ Intercept & 0.701 & 0.01 & 135.259 & $<0.001$ & \\
$\quad$ Raw $\mathrm{CO}_{2}$ (ppm) & & & & \\
\hline
\end{tabular}

Response time was evaluated as the time required for each sensor to shift from background to $90 \%$ of the applied concentration $\left(\mathrm{T}_{90}\right)$. CO sensor $\mathrm{T}_{90}$ increased asymptotically with the concentration change and ranged from $32.3 \pm 4.5 \mathrm{SD}$ seconds with a concentration increase from 3.2 to 8 ppm and $107.0 \pm 4.4$ SD seconds with a concentration increase from 3.2 to $32 \mathrm{ppm}$ (Figure 4), substantially slower than the $\mathrm{T}_{90}$ reported by the manufacturer and that reported for a EC4-500-CO sensor [16] and a Citicell electrolytic $\mathrm{CO}$ sensor $[35,36]$. The $\mathrm{CO}_{2}$ sensor $\mathrm{T}_{90}$ response time also increased asymptotically and ranged from $41.0 \pm 1.7 \mathrm{SD}$ seconds when the concentration increased from 400 to $1000 \mathrm{ppm}$ and $95.0 \pm 2.6 \mathrm{SD}$ seconds when the concentration increased from 400 to $4000 \mathrm{ppm}$ (Figure 4). $\mathrm{T}_{90}$ for the $\mathrm{K}-30 \mathrm{CO}_{2}$ sensor was slower than the $20 \mathrm{~s}$ diffusion time reported by the manufacturer, but slightly faster than the response observed by Yasuda et al. [37]. In comparison to other NDIR sensors, the response time of the K-30 was slower than the Valtronics (model 2015 BMC) sensor $[35,36]$ and the DX6220 $\mathrm{CO}_{2}$ sensor [16]. A slow sensor response may complicate sensor use for the identification of peak gas concentrations and to fully describe the temporal variation in gas concentrations, but are not expected to hinder estimates of total $\mathrm{CO}$ and $\mathrm{CO}_{2}$ fluxes in the smoke plume [16]. 

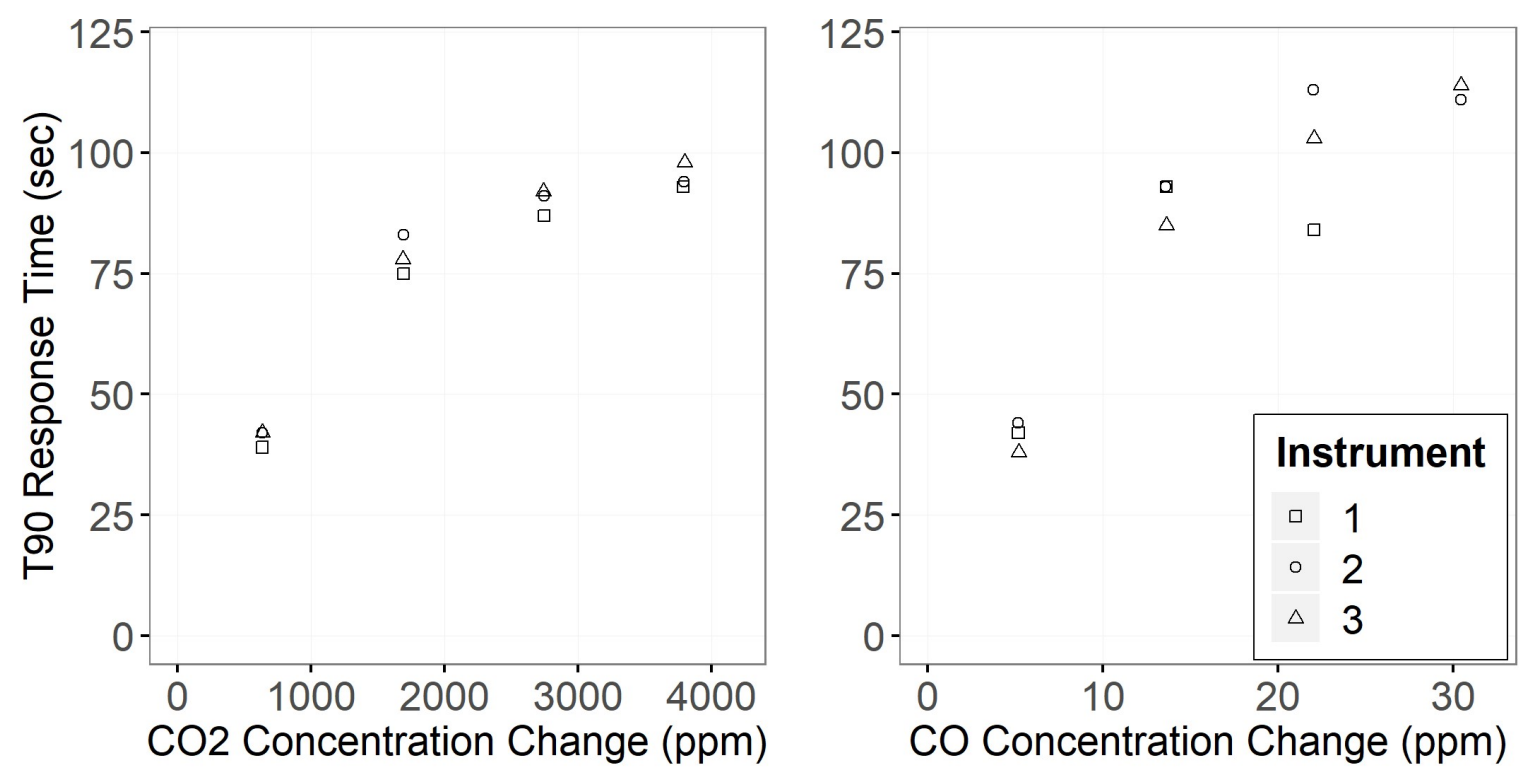

Figure 4. $\mathrm{T}_{90}$ response time for individual carbon dioxide and carbon monoxide gas sensors.

\subsection{Smoke Emissions Sampling}

The performance of our smoke sampling module was demonstrated onboard an sUAS at Tall Timbers Research Station, FL. We collected five canister samples for VOC determination by remotely triggering the valve system at the 50-100 m range; two under prefire ambient conditions and three from the smoke plume during active burning. Regional burning outside of our study area may have contributed to trace VOC concentrations in samples. Prefire ambient samples contained total VOC concentrations of 0.8 and $1.8 \mathrm{ppbv}$, whereas samples collected during active burning contained 7.3 to 24.3 ppbv (Figure 5). The seven most abundant VOCs observed in ambient samples were iso-pentane, benzene, 1-butene + isobutene, isoprene, $\alpha$-pinene, $n$-decane, and n-octane. Samples collected from the smoke plume included a total of 42 VOCs. Six VOCs (i.e., iso-pentane, benzene, 1-butene + isobutene, 1,3-butadiene, toluene, and styrene) accounted for $\sim 71 \%$ and 15 VOCs accounting for $\sim 90 \%$ of total VOCs by ppbv observed during active burning (Figure 5, Supplementary Table S2). Figure 5 presents the top 10 most abundant individual VOCs measured in the ambient air and in the fire smoke plumes. Emission factors were not determined because canister sample concentrations were too low for additional laboratory analysis of total carbon content.

Comparing the $\mathrm{C} 4-\mathrm{C} 10$ VOCs in the fire plumes with those reported in the literature, we found that the top 10 VOCs in our research were observed and reported in other studies [13,38-41]. Dreessen et al. [40] studied emissions transported from a Canadian wildfire that occurred in June 2015. Even though the plume was aged and diluted, high concentrations of isoprene, benzene, and xylenes were observed. Similar to our results, $\alpha$-pinene, benzene, toluene, 1-butene, isoprene, 1,3-butadiene, and $\mathrm{m}+\mathrm{p}$-xylenes were in the top 10 VOCs $(>C 4)$ in a fresh Canadian boreal forest fire plume [41]. Simpson et al. [41] reported $0.99 \pm 032 \mathrm{ppbv}$ of benzene and $0.37 \pm 0.14 \mathrm{ppbv}$ of toluene; these values are a factor of 1.2 to 3.5 lower than our levels (Figure 5). This is most likely due to different meteorological conditions and variation in the dilution of fire emissions during the sampling in fire plumes. In general, the VOC results presented here show good agreement with the literature. 


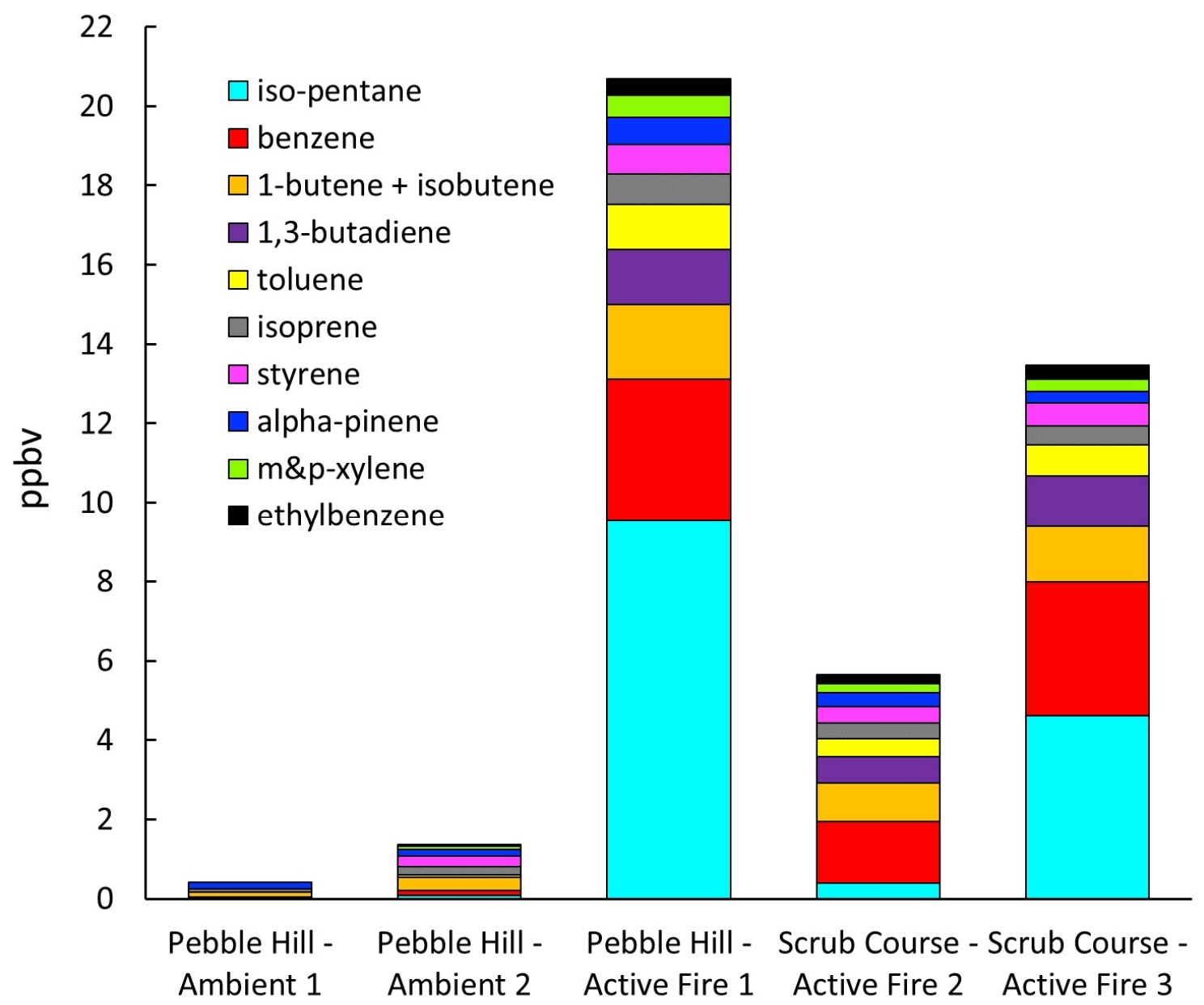

Figure 5. Concentrations of the 10 most abundant volatile organic compounds (VOCs) collected in ambient and fire plume environments at the Tall Timbers Research Station, FL, USA; analytical uncertainty is $\sim 8 \%$ for all VOCs.

\subsection{Smoke Emissions Sensing}

The performance of our smoke sensing module was demonstrated in a near-ground (8-m height above ground) deployment of the instrument at Sycan Marsh Preserve, OR, USA. Prior to the burn, $\mathrm{CO}$ and $\mathrm{CO}_{2}$ sensors were calibrated in the laboratory over a concentration range spanning 3 to 48 ppm for $\mathrm{CO}$ and 400 to $6000 \mathrm{ppm}$ for $\mathrm{CO}_{2}$. Calibrated $\mathrm{CO}$ concentrations in the smoke plume ranged from an ambient minimum of -1 to a peak of $197 \mathrm{ppm}$ (Figure 6); boxcar smoothing constrained the $\mathrm{CO}$ concentration range from -1 to a maximum of $180 \mathrm{ppm}$. Calibrated $\mathrm{CO}_{2}$ concentrations ranged from an ambient minimum of $440 \mathrm{ppm}$ to a maximum of $6326 \mathrm{ppm}$ (Figure 6) and boxcar smoothing constrained the $\mathrm{CO}_{2}$ concentration range from $418 \mathrm{ppm}$ to a peak of $4336 \mathrm{ppm}$. The ranges of the $\mathrm{CO}_{2}$ and $\mathrm{CO}$ concentrations observed at Sycan Marsh Preserve indicate that future deployments will require calibration of the $\mathrm{CO}$ sensor over a greater concentration range while the $\mathrm{CO}_{2}$ sensor's calibration range was appropriate for the application. MCE estimates the efficiency of fuel combustion with smoldering combustion recognized as occurring below a threshold of 0.85 to 0.90 and flaming combustion occurring above this level. Computed using the boxcar smoothed data, the MCE measured in Sycan Marsh Preserve, OR ranged from 0.84 to 1.00 (Figure 6) and generally matches findings from studies that observed flaming combustion in senescent grass and pine litter fuel types $[8,13]$. 

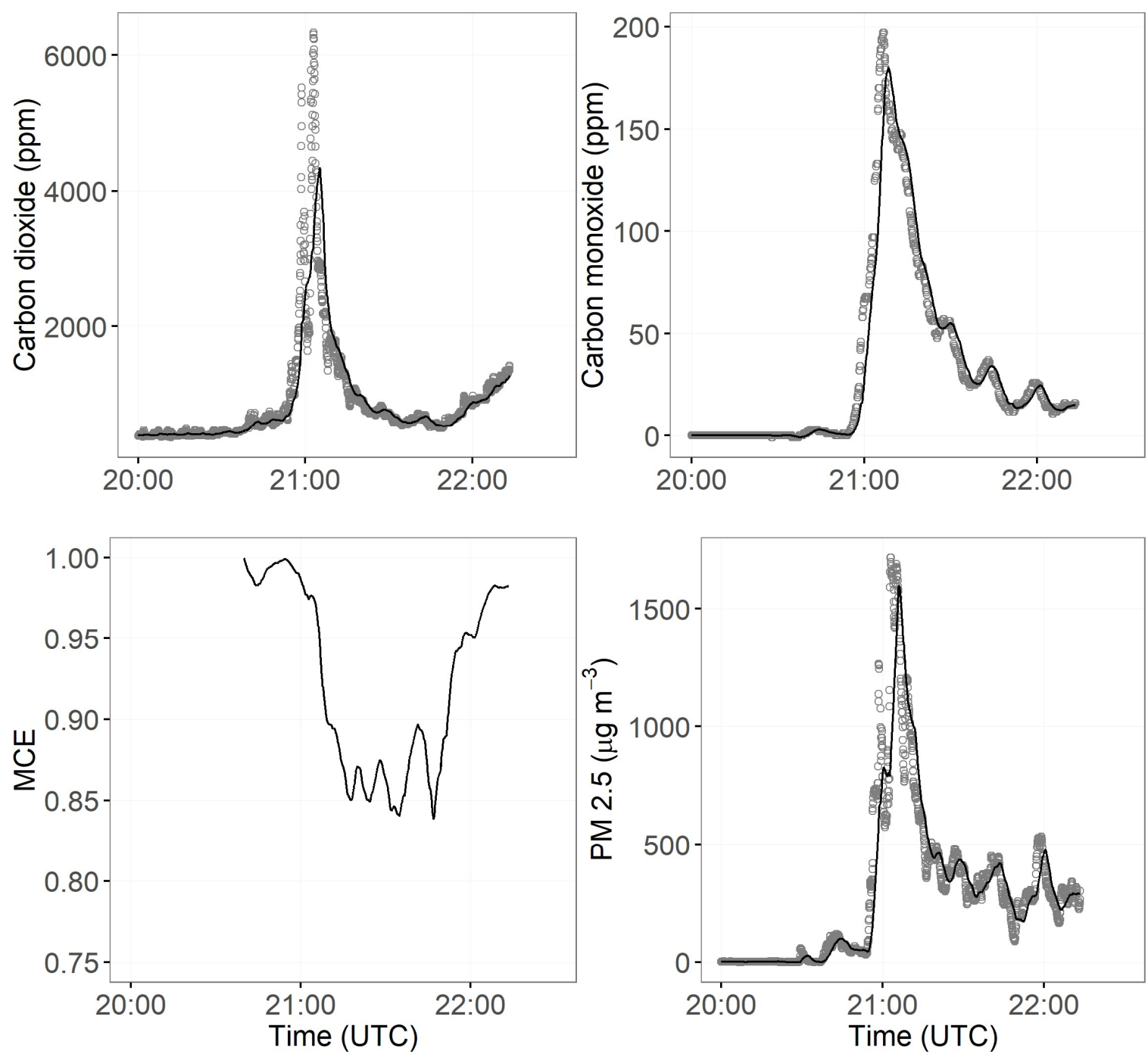

Figure 6. Carbon dioxide, carbon monoxide, modified combustion efficiency (MCE), and $\mathrm{PM}_{2.5}$ (particulate matter $\leq 2.5 \mu \mathrm{m}$ diameter) time series data collected at 8-m height as a head fire passed under the sensing device at Sycan Marsh Preserve, OR, USA. Circles represent raw data points and the line indicates boxcar smoothed data.

$\mathrm{PM}_{2.5}$ mass concentration measurements using the Plantower PMS5003 sensor ranged from 0.0 to $1717 \mu \mathrm{g} \mathrm{m}^{-3}$ and from 0.8 to $1599 \mu \mathrm{g} \mathrm{m}^{-3}$ after boxcar smoothing (Figure 6). As expected, levels observed directly in the smoke plume here were greater than other studies that used the sensor to investigate regional smoke impacts on ambient air conditions during the fire season $[24,26]$. Recent evaluations of the Plantower PMS series (i.e., PMS1003/3003/5003/7003) sensors primarily investigated the sensor at $\mathrm{PM}_{2.5}$ concentrations up to $150 \mu \mathrm{g} \mathrm{m} \mathrm{m}^{-3}$ and found strong correlation with reference monitors [23-25], but one study found correlations were degraded during the wildfire season [24]. Multiple authors noted that raw sensor readings may overestimate PM mass concentrations [23-25] and attributed some overestimation to an increased sampling frequency over reference monitors that permitted greater detection of temporal variation and short lived events [25,26]. Authors also observed a nonlinear response at high concentrations (pronounced above $125 \mu \mathrm{g} \mathrm{m}^{-3}$, [23]) and a high correlation with relative humidity [23,25]. Percent error after calibration ranged from $21 \%$ to $201 \%$ in one study and varied depending on the type of reference monitor used for calibration [23]. $\mathrm{PM}_{2.5}$ mass concentrations observed in our study were very high in comparison with other studies and exceeded the manufacturer's suggested maximum concentration (i.e., $1000 \mu \mathrm{g} \mathrm{m}^{-3}$ ). Therefore, 
we urge caution in interpreting $\mathrm{PM}_{2.5}$ mass concentrations observed directly in smoke plumes using uncalibrated Plantower PMS5003 sensors but highlight the potential utility of investigating temporal trends using the sensor. Further exploration of sensor calibration and environmental correction are necessary to ascertain the sensor's measurement limits in smoke plumes.

Air temperature and relative humidity are essential parameters for predicting fuel flammability and fire behavior, and are routinely collected and used in fire behavior, fire monitoring, and fire modeling studies. Data collected during the experimental burn illustrate the dynamic range of environmental conditions observed with the passage of a flaming front. At $8 \mathrm{~m}$ height, the temperature ranged from 11.5 to $50.5^{\circ} \mathrm{C}$ and the relative humidity ranged from $8.6 \%$ to $43.6 \%$ (Figure 7). Further work is necessary to compare the temperature and humidity sensors used in our sensing instrument with industry standards in fire weather forecasting (i.e., Remote Automated Weather Stations (RAWS)) and to better understand how gas and particulate sensors perform across such a large range of environmental conditions at short time scales.
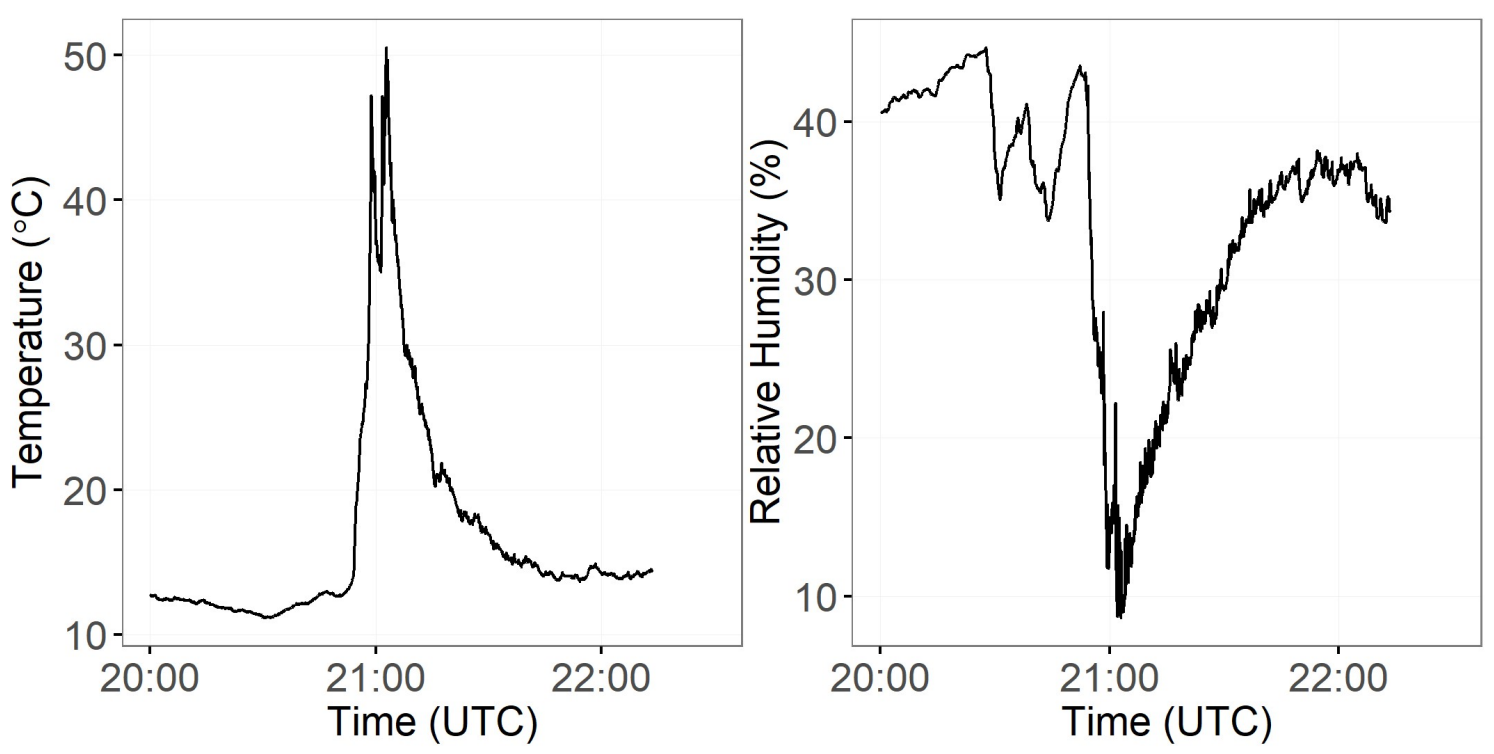

Figure 7. Temperature and relative humidity time series data collected at 8-m height as a head fire passed under the sensing device at Sycan Marsh Preserve, OR, USA.

\section{Conclusions}

We developed a compact lightweight atmospheric sensing and sampling instrument package to measure and monitor smoke emissions from wild and prescribed fires, and tested it in aerial and ground-based deployment during two experimental burns. The instrument effectively collected canister samples from a fire plume onboard an sUAS at distances of 50 to $100 \mathrm{~m}$ from the operator. Laboratory analysis of sample canisters estimated concentrations of 42 VOCs in the smoke plume and can be used in future experiments to identify emissions factors related to these and other VOCs. The sensing instrument module performed well in calibration experiments and in a near-ground field deployment above a flaming front. The instrument is well suited for characterizing gas and meteorological conditions within and adjacent to experimental burn plumes, and can be used to trigger the smoke sampling module under user-specified combustion conditions (e.g., [13]). As outfitted with a weatherproof enclosure and a high-capacity battery, the instrument package is capable of measurements over extended periods on the order of days to weeks.

The integration of air sampling with air quality and meteorological sensing is promising for the development of a methodology for investigating gas and PM fluxes and estimating emissions factors from measurements in wildland fire smoke plumes. Continued evaluation of sensor performance is necessary to minimize measurement uncertainty in the field, where gas concentrations and environmental 
conditions may vary widely over short time scales. Calibration of the $\mathrm{CO}$ and $\mathrm{CO}_{2}$ sensors prior to each sampling campaign is necessary to ensure accurate measurements. Enclosing the sensors in a closed, pump driven system was useful for facilitating the calibration procedure and for preventing variation in airflow across the sensor's diffusion/electrochemical sampling medium. As with other gas sensors used to monitor wildland fire emissions, response time delays may inhibit the sensors' ability to capture the true dynamics of the smoke plume.

We did not directly investigate the influence of the sUAS on gas, PM, and meteorological measurements and recent work shows mixed results depending on the parameter being measured. As one would intuitively expect, rotor wash has been found to exert substantial influence on measurements of wind velocity within close distances to rotors (e.g., [42,43]); however, little impact has been noted for other meteorological measurements (e.g., temperature, relative humidity, pressure) [44]. For gas and particulate measurements, rotors are hypothesized to increase the mixing of air roughly equivalent in size to the rotor's zone of influence, likely increasing the scale of inference of a given sample or measurement to represent a voxel of air roughly equivalent to that size. As long as sensors are placed away or sheltered from high-velocity air currents that could cause mechanical interference with their function, rotor wash is not expected to interfere with PM and gas measurements. Still, further research in necessary to confirm when and to what extent rotor wash influences air quality and emissions measurements.

Further development of the instrument package could include enhancements that broaden the measurement range of the sampling and sensing modules, improve field calibration procedures, prolong measurement times, and deliver real-time data to a cloud-based repository. The use of a pump system to fill sample canisters would boost the sample volume and broaden the suite of laboratory analyses conducted on each sample (e.g., [45]). Additional sensors, such as for methane $\left(\mathrm{CH}_{4}\right)$ and nitrous oxides $\left(\mathrm{NO}, \mathrm{NO}_{2}\right)$ concentrations, would improve carbon emissions quantification and enhance the understanding surrounding the role that nitrogen species play in atmospheric chemistry, especially in ozone $\left(\mathrm{O}_{3}\right)$ production. The instrument package could be adapted for long-term and remote monitoring applications with the incorporation of a long-term power supply and an automated or streamlined calibration methodology. Real-time data transmission and networking would improve data delivery and could provide air quality monitoring and smoke emissions data to air resource and fire managers on actionable time horizons. General improvements, such as reducing the overall instrument size and 3D printing a custom housing, are currently underway.

Supplementary Materials: The following are available online at http:/www.mdpi.com/2571-6255/2/2/32/s1. Figure S1. Instrument configuration in Tall Timbers, FL (left) and Sycan Marsh, OR (right). (a) A prototype of the sensing module and one sample canister mounted below a DJI Matrice 600 Pro hexacopter on a custom aluminum rack. At this time, the instrument was in the early stages of development and as such, only data from the canisters were analyzed. Instrumentation not related to this article is also included in the image. (b) The sensing module as shown in Figure 1 and described in this article was hung in a tree approximately $8 \mathrm{~m}$ above the ground level and collected emissions measurements as the fire passed underneath; Table S1. Specifications for CO, $\mathrm{CO}_{2}$, and PM sensors; Table S2. Volatile organic compound (VOC) concentrations and analytical measurement uncertainty (MU) observed at Tall Timber Research Station, FL, USA in April 2018.

Author Contributions: Conceptualization: A.C.W., K.N.N, A.Y.K., H.M., V.S., and E.M.W.; hardware and software development: K.N.N and J.M.B; data collection: K.N.N, A.C.W., J.M.B., and C.B.; data analysis: K.N.N., and V.S.; writing—original draft preparation: K.N.N. and J.M.B.; writing-review and editing: K.N.N., A.C.W., J.M.B., A.Y.K., H.M., V.S., and E.M.W.

Funding: Funding was provided by the Nevada Governor's Office of Economic Development (GOED) Knowledge Fund (AWD-06-00000051) and the Desert Research Institute. A.C.W, A.Y.K., H.M., and V.S. also acknowledge partial support from NASA ROSES (Grant Number NNX15AI48G), and NSF (Award Number AGS-1544425).

Acknowledgments: The authors thank all staff at the Tall Timbers Research Station and the Jim Castles Applied Research Station, Sycan Marsh Preserve, The Nature Conservancy for their knowledge and support. Special thanks to Dave Grimm and Kevin Hiers at Tall Timbers Research Station, FL; Katie Sauerbrey with the Nature Conservancy, OR; and Russ Parsons with the USDA-Forest Service, Missoula, MT, USA Fire Science Laboratory for providing opportunities to make sUAS flights and test our instrument on experimental burns. We would like to thank Dave Campbell, Marco Giordano, and Irina Lebedeva of the Desert Research Institute (DRI) for helpful 
discussions, laboratory assistance, and use of equipment. Additionally, we appreciate recommendations provided by two thoughtful reviewers that improved the final manuscript.

Conflicts of Interest: The authors declare no conflict of interest.

\section{References}

1. Landrigan, P.J.; Fuller, R.; Acosta, N.J.R.; Adeyi, O.; Arnold, R.; Basu, N.; Baldé, A.B.; Bertollini, R.; Bose-O'Reilly, S.; Boufford, J.I.; et al. The Lancet Commission on pollution and health. Lancet 2018, 391, 462-512. [CrossRef]

2. Chakrabarty, R.K.; Beres, N.D.; Moosmüller, H.; China, S.; Mazzoleni, C.; Dubey, M.K.; Liu, L.; Mishchenko, M.I. Soot superaggregates from flaming wildfires and their direct radiative forcing. Sci. Rep. 2014, 4, 5508. [CrossRef] [PubMed]

3. Hobbs, P.V.; Reid, J.S.; Kotchenruther, R.A.; Ferek, R.J.; Weiss, R. Direct Radiative Forcing by Smoke from Biomass Burning. Science 1997, 275, 1777-1778. [CrossRef]

4. Jiang, Y.; Lu, Z.; Liu, X.; Qian, Y.; Zhang, K.; Wang, Y.; Yang, X.-Q. Impacts of global open-fire aerosols on direct radiative, cloud and surface-albedo effects simulated with CAM5. Atmos. Chem. Phys. 2016, 16, 14805-14824. [CrossRef]

5. Hardy, C.C.; Ottmar, R.D.; Peterson, J.L.; Core, J.E.; Seamon, P. Smoke Management Guide for Prescribed and Wildland Fire: 2001 Edition; PMS 420-2. NFES 1279; National Wildfire Coodination Group: Boise, ID, USA, 2001; p. 226.

6. North, M.; Hurteau, M.; Innes, J. Fire suppression and fuels treatment effects on mixed-conifer carbon stocks and emissions. Ecol. Appl. 2009, 19, 1385-1396. [CrossRef] [PubMed]

7. McClure, C.D.; Jaffe, D.A. US particulate matter air quality improves except in wildfire-prone areas. Proc. Natl. Acad. Sci. USA 2018, 115, 7901-7906. [CrossRef]

8. Urbanski, S.P. Combustion efficiency and emission factors for wildfire-season fires in mixed conifer forests of the northern Rocky Mountains, US. Atmos. Chem. Phys. 2013, 13, 7241-7262. [CrossRef]

9. Akagi, S.K.; Yokelson, R.J.; Wiedinmyer, C.; Alvarado, M.J.; Reid, J.S.; Karl, T.; Crounse, J.D.; Wennberg, P.O. Emission factors for open and domestic biomass burning for use in atmospheric models. Atmos. Chem. Phys. 2011, 11, 4039-4072. [CrossRef]

10. Yokelson, R.J.; Burling, I.R.; Gilman, J.B.; Warneke, C.; Stockwell, C.E.; de Gouw, J.; Akagi, S.K.; Urbanski, S.P.; Veres, P.; Roberts, J.M.; et al. Coupling field and laboratory measurements to estimate the emission factors of identified and unidentified trace gases for prescribed fires. Atmos. Chem. Phys. 2013, 13, 89-116. [CrossRef]

11. Brown, T.; Clements, C.; Larkin, N.; Anderson, K.; Butler, B.; Goodrick, S.; Ichoku, C.; Lamb, B.; Mell, R.; Ottmar, R. Validating the Next Generation of Wildland Fire and Smoke Models for Operational and Research Use-A National Plan; Report 13-S-01-01; Joint Fire Science Program: Boise, ID, USA, 2014; p. 73.

12. Prichard, S.; Larkin, N.S.; Ottmar, R.; French, N.H.F.; Baker, K.; Brown, T.; Clements, C.; Dickinson, M.; Hudak, A.; Kochanski, A.; et al. The Fire and Smoke Model Evaluation Experiment-A Plan for Integrated, Large Fire-Atmosphere Field Campaigns. Atmosphere 2019, 10, 66. [CrossRef]

13. Aurell, J.; Gullett, B.K. Emission Factors from Aerial and Ground Measurements of Field and Laboratory Forest Burns in the Southeastern U.S.: PM2.5, Black and Brown Carbon, VOC, and PCDD/PCDF. Environ. Sci. Technol. 2013, 47, 8443-8452. [CrossRef]

14. Radke, L.F.; Hegg, D.A.; Lyons, J.H.; Brock, C.A.; Hobbs, P.V.; Weiss, R.; Rasmussen, R. Airborne measurements on smokes from biomass burning. Aerosols Clim. 1988, 411-422.

15. Ferrare, R.A.; Fraser, R.S.; Kaufman, Y.J. Satellite measurements of large-scale air pollution: Measurements of forest fire smoke. J. Geophys. Res. Atmos. 1990, 95, 9911-9925. [CrossRef]

16. Zhou, X.; Aurell, J.; Mitchell, W.; Tabor, D.; Gullett, B. A small, lightweight multipollutant sensor system for ground-mobile and aerial emission sampling from open area sources. Atmos. Environ. 2017, 154, 31-41. [CrossRef]

17. Villa, T.F.; Gonzalez, F.; Miljievic, B.; Ristovski, Z.D.; Morawska, L. An Overview of Small Unmanned Aerial Vehicles for Air Quality Measurements: Present Applications and Future Prospectives. Sensors 2016, 16, 1072. [CrossRef]

18. Holder, A.L.; Gullett, B.K.; Urbanski, S.P.; Elleman, R.; O’Neill, S.; Tabor, D.; Mitchell, W.; Baker, K.R. Emissions from prescribed burning of agricultural fields in the Pacific Northwest. Atmos. Environ. 2017, 166, 22-33. [CrossRef] 
19. Aurell, J.; Gullett, B.K.; Tabor, D. Emissions from southeastern U.S. Grasslands and pine savannas: Comparison of aerial and ground field measurements with laboratory burns. Atmos. Environ. 2015, 111, 170-178. [CrossRef]

20. Keating, F.; Mitchell, T.; Kidd, J.; Jacob, J.D. Wildfire Plume Tracking and Dynamics Using UAS. In Proceedings of the AIAA Infotech @ Aerospace, San Diego, CA, USA, 4-8 January 2016.

21. Ottmar, R.D.; Brown, T.J.; French, N.H.F.; Larkin, N.K. Fire and Smoke Model Evaluation Experiment (FASMEE) Study Plan; Joint Fire Sciences Program Project 15-S-01-01; Joint Fire Sciences Program: Boise, ID, USA, 2017; p. 148.

22. NOAA. U.S. Standard Atmosphere, 1976; NOAA: Rockville, MD, USA, 1976.

23. Zheng, T.; Bergin, M.H.; Johnson, K.K.; Tripathi, S.N.; Shirodkar, S.; Landis, M.S.; Sutaria, R.; Carlson, D.E. Field evaluation of low-cost particulate matter sensors in high- and low-concentration environments. Atmos. Meas. Tech. 2018, 11, 4823-4846. [CrossRef]

24. Sayahi, T.; Butterfield, A.; Kelly, K.E. Long-term field evaluation of the Plantower PMS low-cost particulate matter sensors. Environ. Poll. 2019, 245, 932-940. [CrossRef]

25. Bulot, F.M.J.; Johnston, S.J.; Basford, P.J.; Easton, N.H.C.; Apetroaie-Cristea, M.; Foster, G.L.; Morris, A.K.R.; Cox, S.J.; Loxham, M. Long-term field comparison of multiple low-cost particulate matter sensors in an outdoor urban environment. Sci. Rep. 2019, 9, 7497. [CrossRef]

26. Kelleher, S.; Quinn, C.; Miller-Lionberg, D.; Volckens, J. A low-cost particulate matter (PM 2.5$)$ monitor for wildland fire smoke. Atmos. Meas. Tech. 2018, 11, 1087-1097. [CrossRef]

27. Millard, S.P. EnvStats: An R Package for Environmental Statistics; Springer: New York, NY, USA, 2013; ISBN 978-1-4614-8455-4.

28. U.S. EPA. Technical Assistance Document for Sampling and Analysis of Ozone Precursors; United States Environmental Protection Agency: Research Triangle Park, NC, USA, 1998.

29. U.S. EPA. Technical Assistance Document for the National Ambient Air Toxics Trends and Assessment Program, Revision 2; U.S. Environmental Protection Agency: Research Triangle Park, NC, USA, 2009.

30. U.S. EPA. Compendium Method TO-15-Determination of Volatile Organic Compounds (VOCs) in Air Collected in Specially-Prepared Canisters and Analyzed by Gas Chromatography/Mass Spectrometry (GC/MS), 2nd ed.; Office of Research and Development: Cincinnati, OH, USA, 1999.

31. R Core Team. R: A Language and Environment for Statistical Computing; R Foundation for Statistical Computing: Vienna, Austria, 2018; Available online: http://www.R-project.org/ (accessed on 1 August 2018).

32. Grolemund, G.; Hadley, W. Dates and Times Made Easy with lubridate. J. Stat. Softw. 2011, 40, 1-25. [CrossRef]

33. Vaughan, D.; Dancho, M. tibbletime: Time Aware Tibbles, R package Version 0.1.1; 2018. Available online: https:// mran.microsoft.com/snapshot/2018-02-12/web/packages/tibbletime/index.html (accessed on 31 January 2018).

34. Wickham, H. tidyverse: Easily Install and Load the "Tidyverse.", R package Version 1.2; 2017. Available online: https://rdrr.io/cran/tidyverse/ (accessed on 31 January 2018).

35. Ward, D.E.; Hao, W.M.; Susott, R.A.; Babbitt, R.E.; Shea, R.W.; Kauffman, J.B.; Justice, C.O. Effect of fuel composition on combustion efficiency and emission factors for African savanna ecosystems. J. Geophys. Res. Atmos. 1996, 101, 23569-23576. [CrossRef]

36. Ward, D.E.; Susott, R.A.; Kauffman, J.B.; Babbitt, R.E.; Cummings, D.L.; Dias, B.; Holben, B.N.; Kaufman, Y.J.; Rasmussen, R.A.; Setzer, A.W. Smoke and fire characteristics for cerrado and deforestation burns in Brazil: BASE-B Experiment. J. Geophys. Res. 1992, 97, 14601. [CrossRef]

37. Yasuda, T.; Yonemura, S.; Tani, A. Comparison of the Characteristics of Small Commercial NDIR CO2 Sensor Models and Development of a Portable CO2 Measurement Device. Sensors 2012, 12, 3641-3655. [CrossRef]

38. Liu, Y.; Shao, M.; Fu, L.; Lu, S.; Zeng, L.; Tang, D. Source profiles of volatile organic compounds (VOCs) measured in China: Part I. Atmos. Environ. 2008, 42, 6247-6260. [CrossRef]

39. Schauer, J.J.; Kleeman, M.J.; Cass, G.R.; Simoneit, B.R.T. Measurement of Emissions from Air Pollution Sources. 3. C1-C29 Organic Compounds from Fireplace Combustion of Wood. Environ. Sci. Technol. 2001, 35, 1716-1728. [CrossRef]

40. Dreessen, J.; Sullivan, J.; Delgado, R. Observations and impacts of transported Canadian wildfire smoke on ozone and aerosol air quality in the Maryland region on June 9-12, 2015. J. Air Waste Manag. Assoc. 2016, 66, 842-862. [CrossRef]

41. Simpson, I.J.; Akagi, S.K.; Barletta, B.; Blake, N.J.; Choi, Y.; Diskin, G.S.; Fried, A.; Fuelberg, H.E.; Meinardi, S.; Rowland, F.S.; et al. Boreal forest fire emissions in fresh Canadian smoke plumes: $\mathrm{C}_{1}-\mathrm{C}_{10}$ volatile organic compounds (VOCs), $\mathrm{CO}_{2}, \mathrm{CO}, \mathrm{NO}_{2}, \mathrm{NO}, \mathrm{HCN}$ and $\mathrm{CH}_{3} \mathrm{CN}$. Atmos. Chem. Phys. 2011, 11, 6445-6463. [CrossRef] 
42. Prudden, S.; Fisher, A.; Mohamed, A.; Watkins, S. An anemometer for UAS-based atmospheric wind measurements. In Proceedings of the 17th Australian International Aerospace Congress, Melbourne, Australia, 26-28 February 2017; p. 303.

43. Yeo, D.; Shrestha, E.; Paley, D.A.; Atkins, E.M. An Empirical Model of Rotorcrafy UAV Downwash for Disturbance Localization and Avoidance. In Proceedings of the AIAA Atmospheric Flight Mechanics Conference, Kissimmee, FL, USA, 5-9 January 2015; p. 1685.

44. Barbieri, L.; Kral, S.T.; Bailey, S.C.C.; Frazier, A.E.; Jacob, J.D.; Reuder, J.; Brus, D.; Chilson, P.B.; Crick, C.; Detweiler, C.; et al. Intercomparison of Small Unmanned Aircraft System (sUAS) Measurements for Atmospheric Science during the LAPSE-RATE Campaign. Sensors 2019, 19, 2179. [CrossRef]

45. Asher, E.; Hills, A.J.; Hornbrook, R.S.; Stephens, B.B.; Shertz, S.; Gabbard, S.; Apel, E.C. Quality Assessment and airborne measurements in the Colorado Front Range using the Unmanned Whole Air Sampling System (UWASS). In Proceedings of the AGU Fall Meeting, Washington, DC, USA, 10-14 December 2018; Volume 43.

(C) 2019 by the authors. Licensee MDPI, Basel, Switzerland. This article is an open access article distributed under the terms and conditions of the Creative Commons Attribution (CC BY) license (http://creativecommons.org/licenses/by/4.0/). 